\title{
OBESITY: OVERVIEW OF AN EPIDEMIC
}

\author{
Nia Mitchell, MD, Vicki Catenacci, MD, Holly R. Wyatt, MD, and James O. Hill, PhD \\ Anschutz Health \& Wellness Center, University of Colorado Anschutz Medical Campus, Campus \\ Box C263, 13001 E. 17 th Place, Aurora, CO 80045 \\ Vicki Catenacci: Vicki.Catenacci@ucdenver.edu; Holly R. Wyatt: Holly.Wyatt@ucdenver.edu; James O. Hill: \\ James.Hill@ucdenver.edu
}

\section{SYNOPSIS}

Despite growing recognition of the problem, the obesity epidemic continues in the U.S., and obesity rates are increasing around the world. The latest estimates are that approximately $34 \%$ of adults and 15-20\% of children and adolescents in the U.S. are obese. Obesity affects every segment of the U.S. population. Obesity increases the risk of many chronic diseases in children and adults. The epidemic of obesity arose gradually over time, apparently from a small, consistent degree of positive energy balance. Substantial public health efforts are being directed toward addressing obesity, but there is not yet clear evidence of success. Because of the complexity of obesity, it is likely to be one of the most difficult public health issues our society has faced.

The obesity epidemic in the U.S. continues. In the last few years, obesity rates have not increased significantly in some U.S. subpopulations, but it is too soon to tell whether this means that the epidemic has reached maximum levels in these populations. ${ }^{1,2}$ There is clear evidence that obesity rates are increasing in much of the rest of the world. ${ }^{3,4}$ A large amount of research is now directed toward better understanding and treating obesity, and substantial public health efforts are directed toward reducing obesity rates. To date, however, there is little evidence of success in reversing the epidemic in the U.S.

\section{Prevalence of obesity}

Overweight and obesity are defined based on body mass index (BMI), which is determined as weight $(\mathrm{kg})$ divided by height ${ }^{2}(\mathrm{~m})$. Table 1 shows the categories of BMI. A healthy BMI range is $18.5-24.9 \mathrm{~kg} / \mathrm{m}^{2}$. Overweight is defined as a BMI from $25-29.9 \mathrm{~kg} / \mathrm{m}^{2}$, and obesity is defined as BMI $\geq 30 \mathrm{~kg} / \mathrm{m}^{2} .5$ Obesity can be further subdivided based on subclasses of BMI as shown in Table 1. Waist circumference can be used in combination with a BMI value to evaluate health risk for individuals.

The strongest data on obesity prevalence rates over time in the U.S. come from results of the National Health and Nutrition Examination Surveys (NHANES). NHANES periodically collect measured heights and weights in representative samples of the population. The most recent NHANES data were collected during the period 2007-2008. ${ }^{6}$

\footnotetext{
(c) 2011 Elsevier Inc. All rights reserved.

Corresponding author for proof and reprints: Nia Mitchell, MD, Anschutz Health \& Wellness Center, University of Colorado Anschutz Medical Campus, Campus Box C263, 13001 E. 17 ${ }^{\text {th }}$ Place, Aurora, CO 80045, Nia.mitchell@ucdenver.edu.

Publisher's Disclaimer: This is a PDF file of an unedited manuscript that has been accepted for publication. As a service to our customers we are providing this early version of the manuscript. The manuscript will undergo copyediting, typesetting, and review of the resulting proof before it is published in its final citable form. Please note that during the production process errors may be discovered which could affect the content, and all legal disclaimers that apply to the journal pertain.
} 
As shown in Figure 1, obesity rates for adults have been gradually increasing over the past $3+$ decades, with the latest statistics showing that in 2007-2008, approximately $68 \%$ were overweight or obese, and approximately $34 \%$ were obese. $^{1}$

Since the 1970s, the prevalence of obesity has increased throughout the U.S. adult population-among men and women of all ethnic groups, ages, and educational and socioeconomic levels. ${ }^{7}$ While the entire population seems to be getting heavier each year, there is evidence that obesity affects some subgroups in the population to a greater extent than others. For example, African American and Mexican American women have a higher prevalence of obesity (BMI $>30 \mathrm{~kg} / \mathrm{m}^{2}$ ) than Caucasian women, or men of any ethnic background (Table 2). Note that obesity prevalence rates increased over time in all genderethnic groups (Figure 2). Obesity rates are increasing in all income and educational levels (Figures $3 \& 4$ ), but absolute rates are higher in those with low incomes and low education levels. ${ }^{8-10}$ This suggests that the gap among socioeconomic strata for obesity rates may be closing. ${ }^{7}$

The finding that minority and low income individuals are disproportionately affected by obesity is not surprising. The cheapest foods are those containing high levels of fat and sugar. ${ }^{11}$ Thus, the way to get the most calories for the least money is to eat a diet that is high in fat and sugar. This illustrates the interaction of biology and economics in supporting the obesity epidemic. Foods for which we have a high biological preference (i.e., foods high in sugar and high in energy density), and which contribute to overeating, are currently the cheapest and most accessible. ${ }^{11,12}$ Further, minority and low-income individuals may engage in less physical activity than other sectors of the population. ${ }^{13,14}$ In low income populations, problems with neighborhood safety may prevent children from playing outside. People who have more financial resources combat these circumstances more easily and, consequently, are more physically active and less obese than those with fewer resources.

As shown in Figure 5, obesity rates in children and adolescents have continued to increase over the past $3+$ decades. $^{2}$ According to NHANES 2007-2008, $17 \%$ of U.S. children and adolescents between the ages of 2 and 19 years were at or above the $95^{\text {th }}$ percentile for weight. Among children and adolescents, Mexican American males and African American females are more likely to have a higher BMI (Figures $6 a$ and $b$ ). ${ }^{2}$

\section{Health risks associated with obesity}

Obesity negatively affects most bodily systems. It is linked to the most prevalent and costly medical problems seen in our country, including type 2 diabetes, hypertension, coronary artery disease, many forms of cancer, and cognitive dysfunction.

\section{Type 2 diabetes and prediabetes}

BMI, abdominal fat distribution, and weight gain are important risk factors for the development of type 2 diabetes. It is estimated that $90 \%$ of individuals with type 2 diabetes are obese. ${ }^{15}$ It is further estimated that $30 \%$ of U.S. adults have prediabetes. ${ }^{16}$

\section{Dyslipidemia}

Visceral obesity is associated with elevated triglycerides, low HDL cholesterol, and increased small, dense LDL particles. ${ }^{17}$ 


\section{Coronary artery disease (CAD)}

Obese persons, particularly those with abdominal fat distribution, are at increased risk for CAD. The American Heart Association added obesity to its list of major risk factors for CAD in $1998 .{ }^{18}$

\section{Sleep apnea}

Obese men and women are also at high risk for sleep apnea, in which partial or complete upper airway obstruction during sleep leads to episodes of apnea or hypopnea. The interruption in nighttime sleep and repeated episodes of hypoxemia lead to daytime somnolence, morning headache, systemic hypertension, and can eventually result in pulmonary hypertension and right heart failure.

\section{Cognitive dysfunction}

Data about the link between obesity and cognitive dysfunction are mixed. Numerous studies have shown an association between obesity and cognitive dysfunction, including worse executive function ${ }^{19-21}$ and memory deficits. ${ }^{22}$ Although obesity is linked with many diseases that are associated with cognitive dysfunction, some imaging studies have shown lower overall brain volume ${ }^{23}$ and grey 24,25 and white matter ${ }^{26}$ in obese versus normal weight individuals without weight-related comorbidities. Lower brain volumes have also been found in obese individuals with mild cognitive impairment and Alzheimer Disease. ${ }^{27}$ One study that found that obesity in middle age may be associated with developing dementia later in life, but may be protective in older-aged adults. ${ }^{28}$ Another study found overweight and obesity to be protective against cognitive decline associated with mild cognitive impairment, Alzheimer disease, and vascular dementia. ${ }^{29}$ A meta-analysis $^{30}$ of prospective studies that looked at BMI in midlife and dementia showed underweight, overweight, and obesity were all associated with developing dementia later in life. A systematic review of longitudinal population-based studies concluded that higher BMI is likely a risk factor for developing dementia. ${ }^{31}$

\section{Non-alcoholic fatty liver disease}

Obesity is associated with a spectrum of liver disease known as non-alcoholic fatty liver disease (NAFLD) or non-alcoholic steatohepatitis (NASH). Manifestations of this disorder include hepatomegaly, abnormal liver function tests, and abnormal liver histology including macrovesicular steatosis, steatohepatitis, fibrosis and cirrhosis. ${ }^{32,33}$

\section{Cancer}

Overweight and obesity are associated with increased risk of endometrial, esophageal, renal cell, pancreatic, ovarian, breast, colorectal, thyroid, and gallbladder cancers. They also are associated with leukemia, multiple myeloma, non-Hodgkin's lymphoma, and malignant melanoma. ${ }^{34,35}$

\section{Health risks of obesity in children and adolescents}

As more and more children and adolescents are becoming obese, they are beginning to develop risk factors for chronic diseases usually seen much later in life, such as dyslipidemia, hypertension, and hyperinsulinemia. ${ }^{36}$ For example, an increased number of obese children and adolescents are now being diagnosed with type 2 diabetes, ${ }^{37}$ a disease that was virtually nonexistent in this population a few generations ago. Similarly, there is evidence that obesity in children and adolescents facilitates progression of cardiovascular disease. ${ }^{36,38}$ 


\section{How did the epidemic arise?}

In order to understand how the obesity epidemic arose, we will briefly examine how body weight is regulated. The key to understanding body weight regulation is understanding energy balance. The body's state of energy balance is determined by the amount of energy ingested in food in relation to the amount of energy expended in metabolism and physical activity. ${ }^{39,40}$ In order to maintain a stable body weight, energy intake must, over time, exactly equal energy expenditure. Negative energy balance (in which energy expenditure exceeds energy intake) results in weight loss, whereas positive energy balance (in which energy intake exceeds energy expenditure) results in weight gain.

The body appears to have some ability to actively regulate or adjust energy balance since altering one component of energy balance can affect other components. For example, chronic changes in the amount of food consumed lead to changes in metabolism that serve to oppose a change in body weight. ${ }^{41}$ Similarly, chronic changes in physical activity can affect food intake. ${ }^{42,43}$ However, these compensatory physiological changes are not sufficient to completely prevent changes in body weight in the face of strong, persistent positive or negative energy balance. ${ }^{42,43}$ Our physiological system seems to protect more against body weight loss than against body weight gain. This makes sense in that for most of mankind's history, starvation was a much more serious problem than obesity. ${ }^{44}$

Each component of energy balance can be influenced by genetic, epigenetic and environmental factors. We know, for example, that genes can affect each component of energy balance ${ }^{45}$ and can explain some of the differences between individuals in body weight and body composition. While we can conclude that our genes are permissive for weight gain, the gradual weight gain of the population does not seem to be primarily due to genetic factors.

The extent to which the body's physiological regulatory mechanisms serve to maintain a healthy weight depends on the environment. In an environment in which high levels of physical activity are necessary for securing food and shelter and for transportation, and in which food is inconsistently available, the body's physiological regulatory mechanisms appear to work best and serve to help facilitate sufficient food intake to avoid loss of body mass. However, as the environment has gradually changed to one in which high levels of physical activity are not required in daily life and in which food is abundant, inexpensive and served in large portions, the physiological regulation of body weight appears to be insufficient to oppose positive energy balance, weight gain and obesity. In these situations, becoming obese is an adaptation to the environmental conditions and appears to represent a new "settling point".

Obesity researchers are increasingly recognizing the importance of the physical and social environment in facilitating weight gain and obesity. Our current food environment is one in which food is inexpensive, abundant and served in very large portions. ${ }^{40}$ Similarly, we have created a physical activity environment with only a rare need for significant energy expenditure for food, shelter, and transportation. ${ }^{40}$ These environmental influences make it easy for us to overeat and under exercise. The body's physiological system for adjusting energy balance is not sufficiently strong in most people to completely oppose the positive energy balance that results.

Similarly, evidence suggests that obesity is being facilitated by our social environment. Christakis and Fowler demonstrated that socials networks influence whether or not we develop obesity. ${ }^{46}$ With both the physical and social environment facilitating weight gain, it is not surprising that more and more people are gaining weight and becoming obese. 
Our environment arose as an unintended consequence of our societal progress. In fact, our environment was likely shaped in large part because of our biological preferences for high energy foods and lack of biological preference to be physically active. The environment we have created is one to which our ancestors aspired, and includes a consistent supply of goodtasting, inexpensive, available food and the ability to not have to work hard to secure food, shelter and transportation.

The realization that the environment is facilitating obesity has increased interest in modifying the environment to help address the obesity epidemic. While research in this area is only beginning, it represents an exciting new approach to obesity. There are, however, some cautions. First, it is unlikely that modifying the environment alone will solve our problem with obesity. The problem is that so many factors that have contributed to obesity are things that enrich our lives in other ways. For example, we have instant access to information throughout the world through televisions, computers, and personal digital assistants. The fact that these tools contribute to reduced physical activity and thus promote weight gain has only recently been realized. Similarly, the increase in families in which both parents work has increased and contributed to the rise of "fast food restaurants" because few people have the time or energy after work to prepare home cooked meals. New York City mandated that restaurants place calorie counts on menu items to help them control their intake. However, one study found no change in the number of calories purchased at fast food restaurants before and after menu labeling. ${ }^{47}$ It is unlikely that we can ever "go back in time" by giving up these things. It is more likely that we will learn how to modify the environment to support and sustain specific behavioral changes in the population to help people maintain healthy weights.

The need to deal with both the environment and behavior is illustrated in Figure 7. Our biology developed to work best in a different environment - one where food was inconsistent and high levels of physical activity were required to secure food, shelter and for transportation. In previous environments, physical activity was the "driver" for achieving energy balance, and food intake was "pulled" along. ${ }^{39}$ We developed multiply physiological systems to facilitate eating with no need for physiological systems for food restriction, and no need to develop a biological preference to be physically active when physical activity was not required. Essentially, our biology tells us to eat whenever food is available and to rest whenever physical activity is not required. In previous environments, this biology was adequate to allow most people to maintain a healthy weight without conscious effort. Body weight regulation was achieved for most with simple physiological control.

The situation is different in today's environment which requires very little physical activity. Securing food and shelter and moving around our environment do not require the high levels of physical activity required in the past. ${ }^{48}$ Technology has made it possible to be productive while being largely sedentary. Under such conditions, weight gain can only be prevented with conscious efforts to eat less or to be physically active without the need to be physically active. The minority of Americans who are maintaining a healthy weight are likely exercising cognitive control of eating and physical activity patterns to eat less than they would otherwise and to be physically active without the necessity of doing so. In today's environment, maintaining a healthy body weight cannot be left to physiological processes but requires cognitive effort. This does not mean that we should not look for ways to modify the environment to make it easy for people to avoid overeating and a sedentary lifestyle. It does mean that we have to focus not exclusively on changing individual behavior or on changing the environment, but on the combination. We must change the environment to facilitate and sustain the behavior changes required to avoid obesity. 


\section{How much and what type of behavior change is required?}

Hill et al. have argued that the obesity epidemic arose from gradual yearly weight gain in the population produced from a slight, consistent degree of positive energy balance (i.e. energy intake exceeding energy expenditure). ${ }^{48}$ Using longitudinal and cross-sectional data sets, they found that the average U.S. adult has gained an average of 1-2 pounds per year for the last 2-3 decades. Hill et al. ${ }^{48}$ concluded that that weight gain in $90 \%$ of the adult population is due to a positive energy balance of $100 \mathrm{kcal} / \mathrm{day}$ or less. They further suggested that small behavior changes that impact daily energy balance by a little as $100 \mathrm{kcal} / \mathrm{day}$ could help prevent further excessive weight gain in the population.

There is debate in the public health community on whether to focus on changing eating and the food environment or physical activity and the physical activity environment. From an energy balance point of view, it makes no sense to focus on only one side of the equation. While there is a need to modify factors that promote overeating, it may be impossible to manage body weight by food alone in a very sedentary population. In fact, most of the U.S. population may be so physically inactive that it will be virtually impossible for them to eat sufficiently little over the long term to match their low energy expenditure.

\section{Dealing with the complexity of obesity}

The more we understand about the etiology of obesity, the more complex it appears. For example, we have learned that the maternal environment may have lasting consequences on body weight regulation and the development of chronic disease in the offspring. 49 Understanding and addressing obesity requires understanding and appreciating our biology, our behavior, our environment, and our culture. We have major efforts underway in our scientific community to focus on each of these areas, but few efforts to integrate among areas. Focusing only on one of these major areas is likely to be incomplete. We need to understand the biology of obesity, but only in rare cases is obesity the result of a biological "defect". Similarly, we need to understand better how to change behavior, but to do this we have to appreciate our biology and the environment in which we live. Figuring out how to change the environment to make a difference in obesity will also require appreciation of biology and behavior. Finally, obesity even involves the ways we have constructed our society, our shared collective worldview, and the material base of this worldview. We need to better understand the complex economic factors that are supporting our current diet and physical activity patterns, and we need to think about how these could be changed to support a healthier lifestyle. ${ }^{12,50,51} \mathrm{We}$ must begin to examine ways that we can replace those aspects of society that support obesity with those that support healthier lifestyles. We need to begin to construct a vision of what our society would look like if it supported maintenance of a healthy body weight and supported obesity prevalence rates that were acceptable.

\section{Strategies for getting out of the obesity epidemic}

What strategies could we use to reverse the obesity epidemic? Figure 8 , adopted from the work of Dr. Stephan Rossner, illustrates some possibilities. If we do nothing, the weight of the population will continue to increase until all of those who are not genetically protected will be overweight or obese. How might we reduce obesity prevalence rates to acceptable levels over time?

One possibility is to reduce weight in many of those people who are already overweight or obese. The problem is that our ability to produce and maintain substantial weight loss is not good. ${ }^{52-54}$ Most people who lose large amounts of weight regain this weight completely within a few years. ${ }^{52-54}$ Rarely does anyone transition permanently from the obese category 
to the healthy weight category. One meta-analysis showed that obese people were $3.2 \%$ below their baseline weight at 5 years, which reflected the maintenance of $23 \%$ of their initial weight loss. ${ }^{55}$ Another study of NHANES data concluded that only $17 \%$ of overweight or obese adults maintained a weight loss of at least $10 \%$ for 1 year. ${ }^{56}$ Health care professionals now recommend that weight loss goals of $5-10 \%$ of initial weight can be achieved and maintained in many people. ${ }^{57}$ The bottom line is that currently we do not have a good ability to produce and maintain significant weight loss in large numbers of overweight and obese individuals. While we will certainly improve our obesity treatment strategies over time, we cannot at present rely on this treatment to reverse the obesity epidemic.

It is possible to reverse the obesity epidemic through prevention. This could begin with stopping the gradual weight gain in the adult population and identifying and stopping excessive weight gain in children. We have previously demonstrated that weight gain in most adults can be prevented with small changes in energy balance of $100 \mathrm{kcal} / \mathrm{day}$ or less. ${ }^{39}$ Preventing further weight gain in the population could have significant positive impacts on health and health care costs of the population, since increasing BMI is associated with increasing risk of chronic disease and with increasing health care costs. ${ }^{58}$

Wang and colleagues ${ }^{59}$ have estimated that children and adolescents need to shift the energy balance by $\leq 150 \mathrm{kcal} /$ day to prevent weight gain. This amount is likely significantly less than that required for substantial weight loss.

We and others have found some success with the small changes approach to preventing excessive weight gain. Rodearmel et al. demonstrated in two prospective studies that small changes in diet and physical activity could reduce excessive weight gain in overweight and obese children when delivered as part of a family intervention. ${ }^{60,61}$ The ASPIRE trial showed that overweight and obese sedentary adults randomized to a 16-week intervention that used small changes in diet and physical activity lost significantly more weight than both the standard didactic group or control group. ${ }^{62}$ Although weight loss for the small changes group was small (average of $4.62 \mathrm{~kg}$ ), it was clinically significant (5\% of body weight). Importantly, the small changes group also maintained weight loss, decreased waist circumference, and abdominal fat loss at three months post-treatment. In addition, a 12-week small changes telephonic intervention was evaluated in sedentary obese veterans. ${ }^{63}$

Although not a randomized trial, results were similar to the ASPIRE trial in that participants showed significant weight loss.

The cause of preventing and treating childhood obesity was given a boost when the First Lady, Michelle Obama, decided to concentrate on childhood obesity. The White House Task Force on Childhood Obesity was formed, and in May 2010 it released its report which recommends a multi-pronged approach to end childhood obesity in one generation. The recommendations include preconceptual and prenatal care, suggestions for early childhood, helping parents and caregivers to make better choices, improving food choices in school cafeterias, increasing access to healthy foods, and increasing physical activity. ${ }^{64}$

By using a strategy of stopping excessive weight gain, the prevalence of obesity would decrease with each successive generation. While it may take decades to reverse the obesity epidemic using this strategy, the positive view is that we may actually be able to produce and maintain the behavior changes that would be required to stop excessive weight gain. This can be done through a combination of focusing on specific behavior change and modifying the environment in ways to support and sustain the desired behavior changes. 


\section{Summary}

The obesity epidemic in the U.S. has proven difficult to reverse. We have not been successful in helping people sustain the eating and physical activity patterns that we believe are needed in order to maintain a healthy body weight. There is growing recognition that we will not be able to sustain healthy lifestyles until we are able to address the environment and culture that currently support unhealthy lifestyles.

Addressing obesity requires an understanding of energy balance. From an energy balance approach it should be easier to prevent obesity than to reverse it. Further, from an energy balance point of view, it may not be possible to solve the problem by focusing on food alone. Currently, energy requirements of much of the population may be below the level of energy intake than can reasonably be maintained over time.

Many initiatives are underway to revise how we build our communities, the ways we produce and market our foods, and the ways we inadvertently promote sedentary behavior. Efforts are underway to prevent obesity in schools, worksites and communities. It is probably too early to evaluate these efforts, but there have been no large scale successes in preventing obesity to date.

There is reason to be optimistic about dealing with obesity. We have successfully addressed many previous threats to public health. It was probably inconceivable in the 1950s to think that major public health initiatives could have such a dramatic effect on reducing the prevalence of smoking in the United States. Yet, this serious problem was addressed by a combination of strategies involving public health, economics, political advocacy, behavior change, and environmental change. Similarly, Americans have been persuaded to use seat belts and recycle, addressing two other challenges to public health. ${ }^{65}$

But, there is also reason to be pessimistic. Certainly, we can learn from our previous efforts for social change, but we must realize that our challenge with obesity may be greater. In the other examples cited above, we had clear goals in mind. Our goals were to stop smoking, increase the use seatbelts and increase recycling. The difficulty of achieving these goals should not be minimized, but they were clear and simple goals. With obesity, there is no clear agreement about goals. Moreover, experts do not agree on which strategies should be implemented on a widespread basis to achieve the behavioral changes in the population needed to reverse the high prevalence rates of obesity. We need a successful model that will help us understand what to do to address obesity. A good example is the recent HEALTHY study ${ }^{66}$ This comprehensive intervention was implemented in several schools and aimed to reduce obesity by concentrating on behavior and environment. This intervention delivered most of the strategies we believe to be effective in schools. While the program produced a reduction in obesity, this reduction was not greater than the reduction seen in the control schools that did not receive the intervention. This does not mean we should not be intervening in schools, but rather that it may require concerted efforts across behavioral settings to reduce obesity.

But, while we need successful models, there is a great deal of urgency in responding to the obesity epidemic. A great example is the effort to get menu labeling in restaurants. This is moving rapidly toward being national policy. While the evaluation of this strategy is still ongoing, it is not clear what impact it will have on obesity rates. We should be encouraging efforts like this, but we must evaluate them rigorously.

Once we get serious about addressing obesity, it will likely take decades to reverse obesity rates to levels seen 30 years ago. Meanwhile, the prevalence of overweight and obesity remains high and quite likely will continue to increase. 


\section{Acknowledgments}

This work was supported by grants \# DK02703, DK42549, and DK48520 from the National Institutes of Health.

\section{References}

1. Flegal KM, Carroll MD, Ogden CL, Curtin LR. Prevalence and trends in obesity among US adults, 1999-2008. JAMA. 2010; 303:235-41. [PubMed: 20071471]

2. Ogden CL, Carroll MD, Curtin LR, Lamb MM, Flegal KM. Prevalence of high body mass index in US children and adolescents, 2007-2008. JAMA. 2010; 303:242-9. [PubMed: 20071470]

3. James WP. WHO recognition of the global obesity epidemic. Int J Obes (Lond). 2008; 32 (Suppl 7):S120-6. [PubMed: 19136980]

4. Finucane MM, Stevens GA, Cowan MJ, et al. National, regional, and global trends in body-mass index since 1980: systematic analysis of health examination surveys and epidemiological studies with 960 country-years and 9.1 million participants. Lancet. 2011; 377:557-67. [PubMed: 21295846]

5. Clinical guidelines on the identification, evaluation, and treatment of overweight and obesity in adults: executive summary. Expert Panel on the Identification, Evaluation, and Treatment of Overweight in Adults. Am J Clin Nutr. 1998; 68:899-917. [PubMed: 9771869]

6. Flegal K, Carroll M, Ogden C, Curtin L. Prevalence and trends in obesity among US adults, 19992008. JAMA. 2010; 303:235-41. [PubMed: 20071471]

7. Zhang Q, Wang Y. Trends in the association between obesity and socioeconomic status in U.S. adults: 1971 to 2000. Obes Res. 2004; 12:1622-32. [PubMed: 15536226]

8. Molarius A, Seidell JC, Sans S, Tuomilehto J, Kuulasmaa K. Educational level, relative body weight, and changes in their association over 10 years: an international perspective from the WHO MONICA Project. Am J Public Health. 2000; 90:1260-8. [PubMed: 10937007]

9. Sobal J, Stunkard AJ. Socioeconomic status and obesity: a review of the literature. Psychol Bull. 1989; 105:260-75. [PubMed: 2648443]

10. Truong, K.; Sturm, R. Does the obesity epidemic widen sociodemographic health disparities in the US?. Rand Institute; 2004.

11. Drewnowski A, Specter SE. Poverty and obesity: the role of energy density and energy costs. Am J Clin Nutr. 2004; 79:6-16. [PubMed: 14684391]

12. Cawley J. An economic framework for understanding physical activity and eating behaviors. Am J Prev Med. 2004; 27:117-25. [PubMed: 15450622]

13. Harper S, Lynch J. Trends in socioeconomic inequalities in adult health behaviors among U.S. states, 1990-2004. Public Health Rep. 2007; 122:177-89. [PubMed: 17357360]

14. Gordon-Larsen P, Nelson MC, Page P, Popkin BM. Inequality in the built environment underlies key health disparities in physical activity and obesity. Pediatrics. 2006; 117:417-24. [PubMed: 16452361]

15. Allison DB, Saunders SE. Obesity in North America. An overview. Med Clin North Am. 2000; 84:305-32. v. [PubMed: 10793644]

16. Geiss LS, James C, Gregg EW, Albright A, Williamson DF, Cowie CC. Diabetes risk reduction behaviors among U.S. adults with prediabetes. Am J Prev Med. 2010; 38:403-9. [PubMed: 20307809]

17. Terry RB, Wood PD, Haskell WL, Stefanick ML, Krauss RM. Regional adiposity patterns in relation to lipids, lipoprotein cholesterol, and lipoprotein subfraction mass in men. J Clin Endocrinol Metab. 1989; 68:191-9. [PubMed: 2909551]

18. Eckel RH, Krauss RM. American Heart Association call to action: obesity as a major risk factor for coronary heart disease. AHA Nutrition Committee Circulation. 1998; 97:2099-100.

19. Boeka AG, Lokken KL. Neuropsychological performance of a clinical sample of extremely obese individuals. Arch Clin Neuropsychol. 2008; 23:467-74. [PubMed: 18448310]

20. Fergenbaum JH, Bruce S, Lou W, Hanley AJ, Greenwood C, Young TK. Obesity and lowered cognitive performance in a Canadian First Nations population. Obesity (Silver Spring). 2009; 17:1957-63. [PubMed: 19478788] 
21. Gunstad J, Paul RH, Cohen RA, Tate DF, Spitznagel MB, Gordon E. Elevated body mass index is associated with executive dysfunction in otherwise healthy adults. Compr Psychiatry. 2007; 48:57-61. [PubMed: 17145283]

22. Gunstad J, Paul RH, Cohen RA, Tate DF, Gordon E. Obesity is associated with memory deficits in young and middle-aged adults. Eat Weight Disord. 2006; 11:e15-9. [PubMed: 16801734]

23. Raji CA, Ho AJ, Parikshak NN, et al. Brain structure and obesity. Hum Brain Mapp. 2010; 31:353-64. [PubMed: 19662657]

24. Taki Y, Kinomura S, Sato K, et al. Relationship between body mass index and gray matter volume in 1,428 healthy individuals. Obesity (Silver Spring). 2008; 16:119-24. [PubMed: 18223623]

25. Pannacciulli N, Del Parigi A, Chen K, Le DS, Reiman EM, Tataranni PA. Brain abnormalities in human obesity: a voxel-based morphometric study. Neuroimage. 2006; 31:1419-25. [PubMed: 16545583]

26. Stanek KM, Grieve SM, Brickman AM, et al. Obesity is associated with reduced white matter integrity in otherwise healthy adults. Obesity (Silver Spring). 2011; 19:500-4. [PubMed: 21183934]

27. Ho AJ, Raji CA, Becker JT, et al. Obesity is linked with lower brain volume in 700 AD and MCI patients. Neurobiol Aging. 2010; 31:1326-39. [PubMed: 20570405]

28. Fitzpatrick AL, Kuller LH, Lopez OL, et al. Midlife and late-life obesity and the risk of dementia: cardiovascular health study. Arch Neurol. 2009; 66:336-42. [PubMed: 19273752]

29. Doruk H, Naharci MI, Bozoglu E, Isik AT, Kilic S. The relationship between body mass index and incidental mild cognitive impairment, Alzheimer's disease and vascular dementia in elderly. J Nutr Health Aging. 2010; 14:834-8. [PubMed: 21125201]

30. Anstey KJ, Cherbuin N, Budge M, Young J. Body mass index in midlife and late-life as a risk factor for dementia: a meta-analysis of prospective studies. Obes Rev. 2011; 12:e426-37. [PubMed: 21348917]

31. Gorospe EC, Dave JK. The risk of dementia with increased body mass index. Age Ageing. 2007; 36:23-9. [PubMed: 17124253]

32. Matteoni CA, Younossi ZM, Gramlich T, Boparai N, Liu YC, McCullough AJ. Nonalcoholic fatty liver disease: a spectrum of clinical and pathological severity. Gastroenterology. 1999; 116:14139. [PubMed: 10348825]

33. Adler M, Schaffner F. Fatty liver hepatitis and cirrhosis in obese patients. Am J Med. 1979; 67:811-6. [PubMed: 507094]

34. Reeves GK, Pirie K, Beral V, et al. Cancer incidence and mortality in relation to body mass index in the Million Women Study: cohort study. BMJ. 2007; 335:1134. [PubMed: 17986716]

35. Renehan AG, Tyson M, Egger M, Heller RF, Zwahlen M. Body-mass index and incidence of cancer: a systematic review and meta-analysis of prospective observational studies. Lancet. 2008; 371:569-78. [PubMed: 18280327]

36. Freedman DS, Mei Z, Srinivasan SR, Berenson GS, Dietz WH. Cardiovascular risk factors and excess adiposity among overweight children and adolescents: the Bogalusa Heart Study. J Pediatr. 2007; 150:12-7.e2. [PubMed: 17188605]

37. Fagot-Campagna A, Pettitt DJ, Engelgau MM, et al. Type 2 diabetes among North American children and adolescents: an epidemiologic review and a public health perspective. J Pediatr. 2000; 136:664-72. [PubMed: 10802501]

38. Freedman DS, Dietz WH, Srinivasan SR, Berenson GS. The relation of overweight to cardiovascular risk factors among children and adolescents: the Bogalusa Heart Study. Pediatrics. 1999; 103:1175-82. [PubMed: 10353925]

39. Peters JC, Wyatt HR, Donahoo WT, Hill JO. From instinct to intellect: the challenge of maintaining healthy weight in the modern world. Obes Rev. 2002; 3:69-74. [PubMed: 12120422]

40. Hill JO, Wyatt HR, Melanson EL. Genetic and environmental contributions to obesity. Med Clin North Am. 2000; 84:333-46. [PubMed: 10793645]

41. Horton TJ, Drougas H, Brachey A, Reed GW, Peters JC, Hill JO. Fat and carbohydrate overfeeding in humans: different effects on energy storage. Am J Clin Nutr. 1995; 62:19-29. [PubMed: 7598063] 
42. Blundell JE, Stubbs RJ, Hughes DA, Whybrow S, King NA. Cross talk between physical activity and appetite control: does physical activity stimulate appetite? Proc Nutr Soc. 2003; 62:651-61. [PubMed: 14692601]

43. Epstein LH, Paluch RA, Consalvi A, Riordan K, Scholl T. Effects of manipulating sedentary behavior on physical activity and food intake. J Pediatr. 2002; 140:334-9. [PubMed: 11953732]

44. Prentice AM. Fires of ife: the struggles of an ancient metabolism in a modern world. Nutrition Bulletin. 2001; 26:13-27.

45. Bouchard, C.; Perusse, L.; Rice, T.; Rao, D. Genetics of Human Obesity 2004. In: Bray, G.; Bouchard, C., editors. Handbook of Obesity. Narcel Dekker, Inc; New York: 2004. p. 157-200.

46. Christakis NA, Fowler JH. The spread of obesity in a large social network over 32 years. N Engl J Med. 2007; 357:370-9. [PubMed: 17652652]

47. Elbel B, Kersh R, Brescoll VL, Dixon LB. Calorie labeling and food choices: a first look at the effects on low-income people in New York City. Health Aff (Millwood). 2009; 28:w1110-21. [PubMed: 19808705]

48. Hill JO, Wyatt HR, Reed GW, Peters JC. Obesity and the environment: where do we go from here? Science. 2003; 299:853-5. [PubMed: 12574618]

49. Barker DJ, Gluckman PD, Godfrey KM, Harding JE, Owens JA, Robinson JS. Fetal nutrition and cardiovascular disease in adult life. Lancet. 1993; 341:938-41. [PubMed: 8096277]

50. Sturm R. The economics of physical activity: societal trends and rationales for interventions. Am J Prev Med. 2004; 27:126-35. [PubMed: 15450623]

51. Hill JO, Sallis JF, Peters JC. Economic analysis of eating and physical activity: a next step for research and policy change. Am J Prev Med. 2004; 27:111-6. [PubMed: 15450621]

52. Wing RR, Hill JO. Successful weight loss maintenance. Annu Rev Nutr. 2001; 21:323-41. [PubMed: 11375440]

53. Brownell KD. Diet, exercise and behavioural intervention: the nonpharmacological approach. Eur J Clin Invest. 1998; 28(Suppl 2):19-21. discussion 2. [PubMed: 9777323]

54. Wadden TA, Foster GD, Letizia KA. One-year behavioral treatment of obesity: comparison of moderate and severe caloric restriction and the effects of weight maintenance therapy. J Consult Clin Psychol. 1994; 62:165-71. [PubMed: 8034818]

55. Anderson JW, Konz EC, Frederich RC, Wood CL. Long-term weight-loss maintenance: a metaanalysis of US studies. Am J Clin Nutr. 2001; 74:579-84. [PubMed: 11684524]

56. Kraschnewski JL, Boan J, Esposito J, et al. Long-term weight loss maintenance in the United States. Int J Obes (Lond). 2010; 34:1644-54. [PubMed: 20479763]

57. The Surgeon General's call to action to prevent and decrease overweight and obesity. US Department of Health and Human Services; 2000.

58. Sturm R, Ringel JS, Andreyeva T. Increasing obesity rates and disability trends. Health Aff (Millwood). 2004; 23:199-205. [PubMed: 15046144]

59. Wang YC, Gortmaker SL, Sobol AM, Kuntz KM. Estimating the energy gap among US children: a counterfactual approach. Pediatrics. 2006; 118:e1721-33. [PubMed: 17142497]

60. Rodearmel SJ, Wyatt HR, Barry MJ, et al. A family-based approach to preventing excessive weight gain. Obesity (Silver Spring). 2006; 14:1392-401. [PubMed: 16988082]

61. Rodearmel SJ, Wyatt HR, Stroebele N, Smith SM, Ogden LG, Hill JO. Small changes in dietary sugar and physical activity as an approach to preventing excessive weight gain: the America on the Move family study. Pediatrics. 2007; 120:e869-79. [PubMed: 17908743]

62. Lutes LD, Winett RA, Barger SD, et al. Small changes in nutrition and physical activity promote weight loss and maintenance: 3-month evidence from the ASPIRE randomized trial. Ann Behav Med. 2008; 35:351-7. [PubMed: 18568379]

63. Damschroder LJ, Lutes LD, Goodrich DE, Gillon L, Lowery JC. A small-change approach delivered via telephone promotes weight loss in veterans: results from the ASPIRE-VA pilot study. Patient Educ Couns. 2010; 79:262-6. [PubMed: 19910151]

64. Solving the problem of childhood obesity within a generation. May. 2010 White House Task Force on Childhood Obesity Reoprt to the President. 
65. Economos CD, Brownson RC, DeAngelis MA, et al. What lessons have been learned from other attempts to guide social change? Nutr Rev. 2001; 59:S40-56. discussion S7-65. [PubMed: 11360889]

66. Foster GD, Linder B, Baranowski T, et al. A school-based intervention for diabetes risk reduction. N Engl J Med. 2010; 363:443-53. [PubMed: 20581420]

Psychiatr Clin North Am. Author manuscript; available in PMC 2012 December 1. 


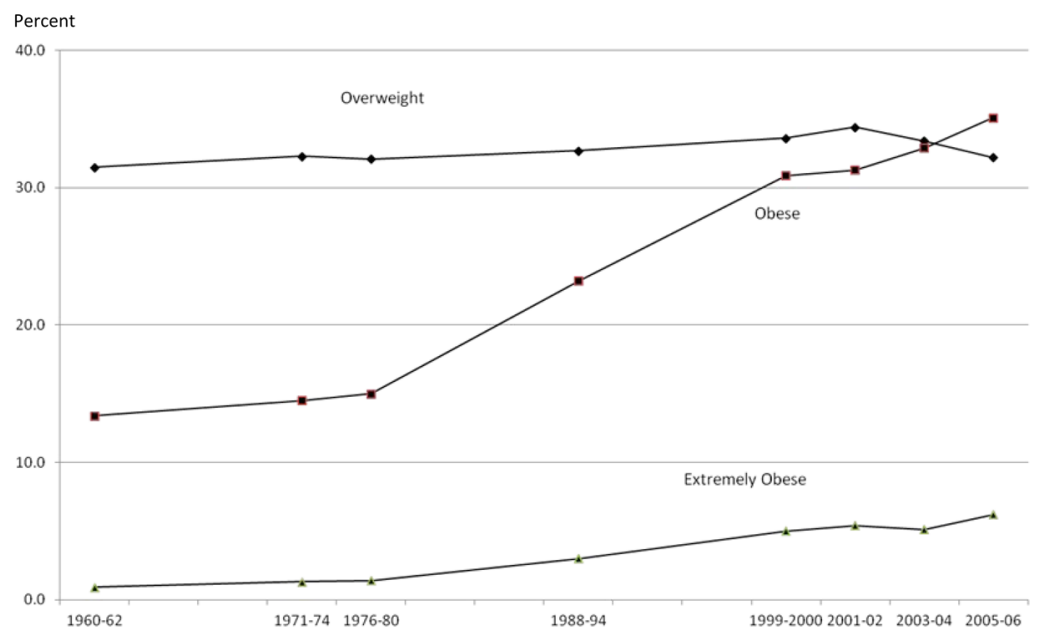

Fig 1.

Trends in overweight, obesity and extreme obesity, ages 20-74 years. Note: Age-adjusted by the direct method to the year 2000 US Bureau of the Census using age groups 20-39, 40-59 and 60-74 years. Pregnant females excluded. Overweight defined as $25<=\mathrm{BMI}<30$; obesity defined as $\mathrm{BMI}>=30$; extreme obesity defined as $\mathrm{BMI}>=40$. 


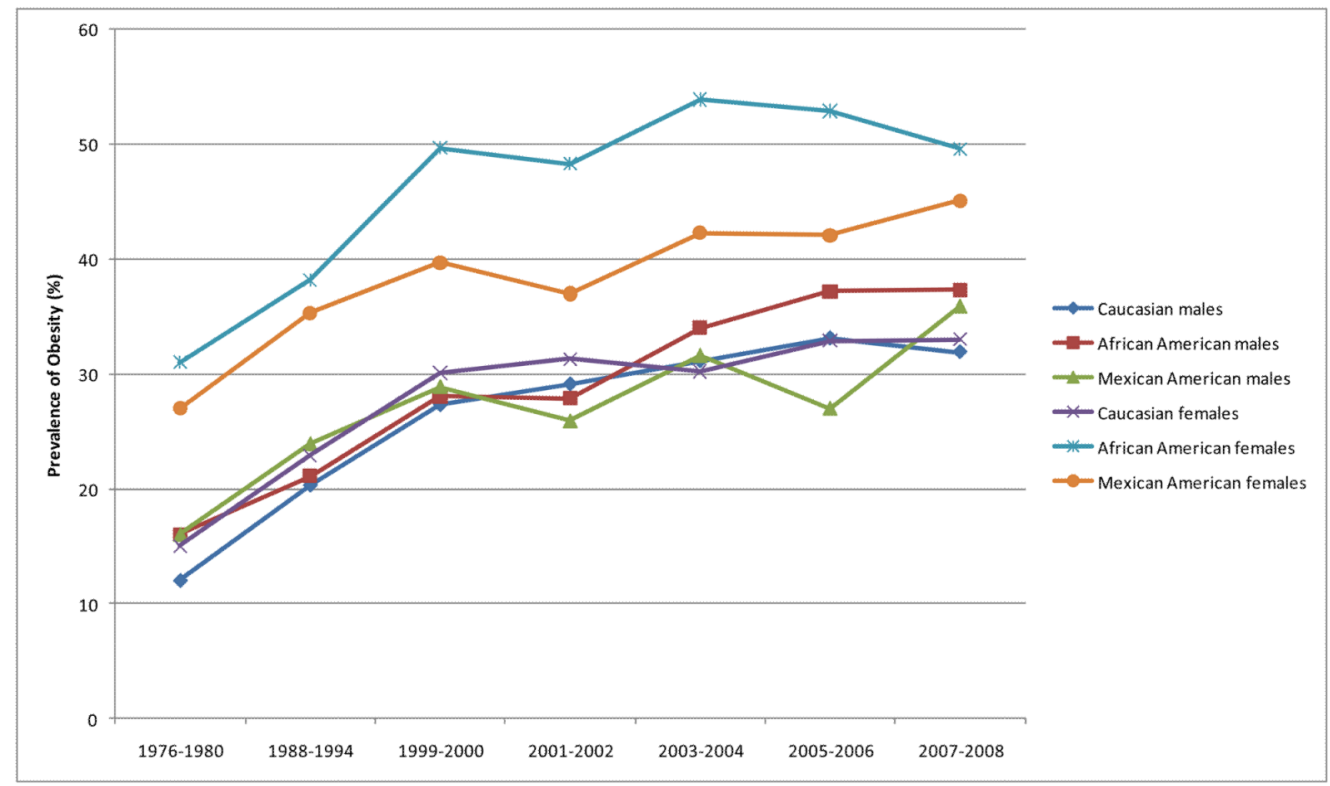

Fig. 2.

Obesity prevalence rates increased over time in all gender-ethnic groups. 


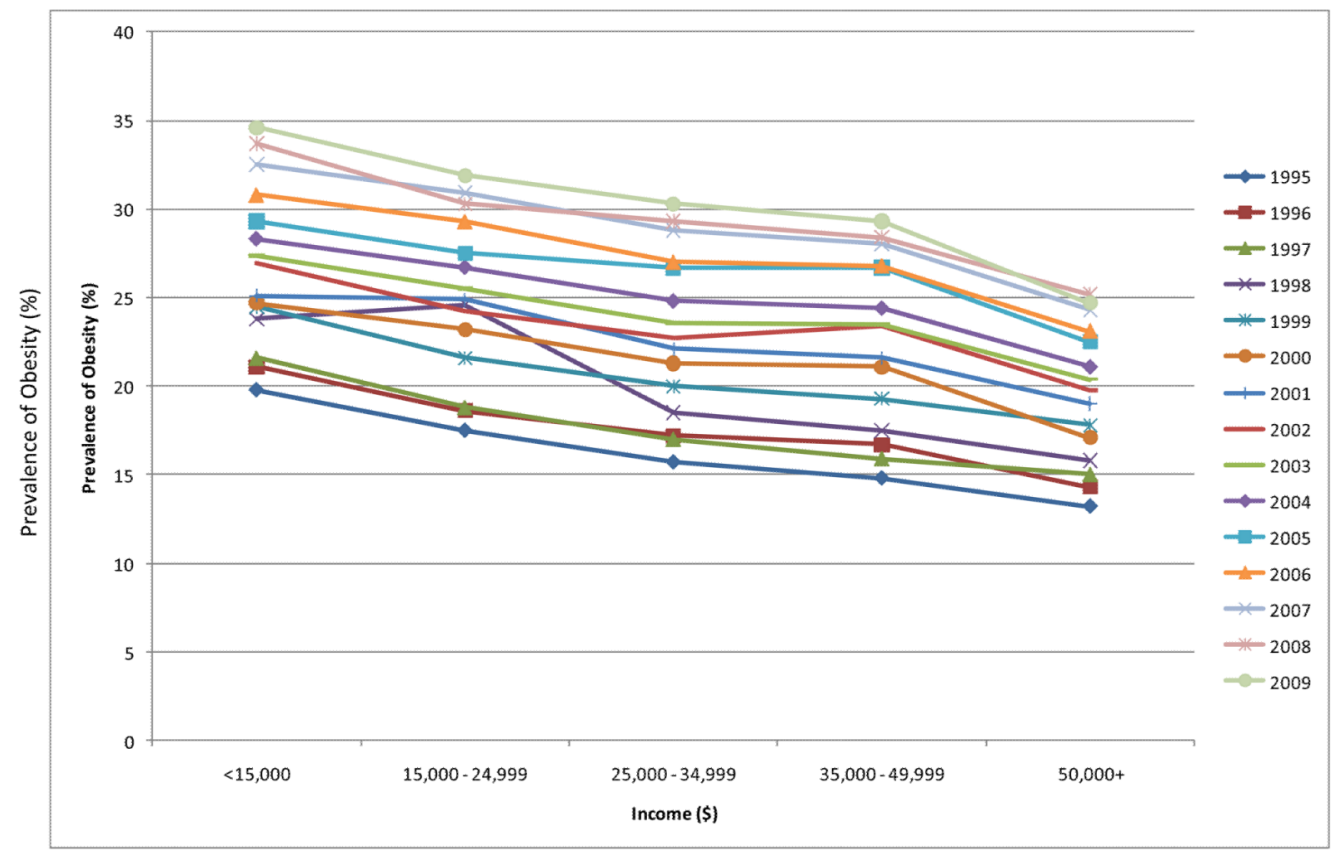

Fig. 3.

Obesity rates are the same at all income levels. 


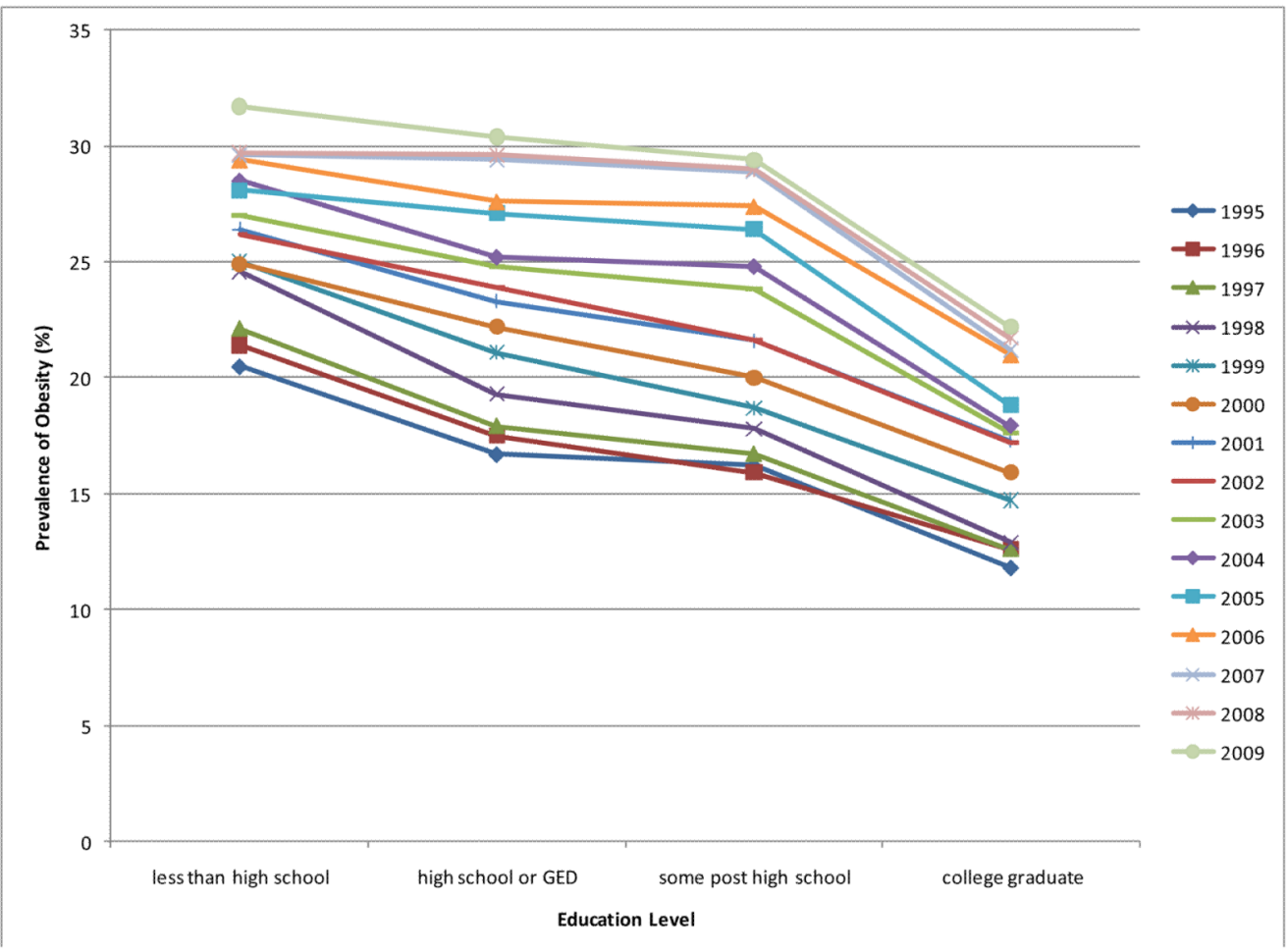

Fig. 4.

Obesity rates are the same at all education levels. 


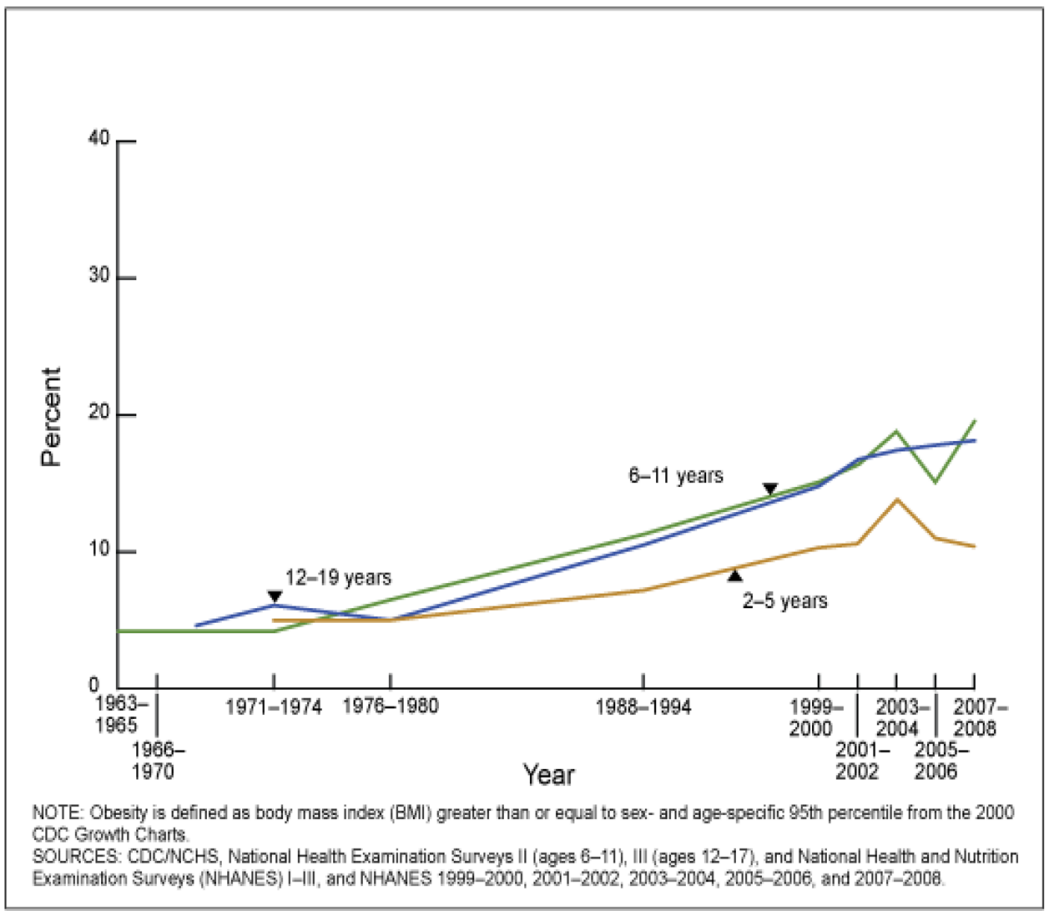

Fig. 5.

Obesity rates in children and adolescents have continued to increase over the past 3 decades. 

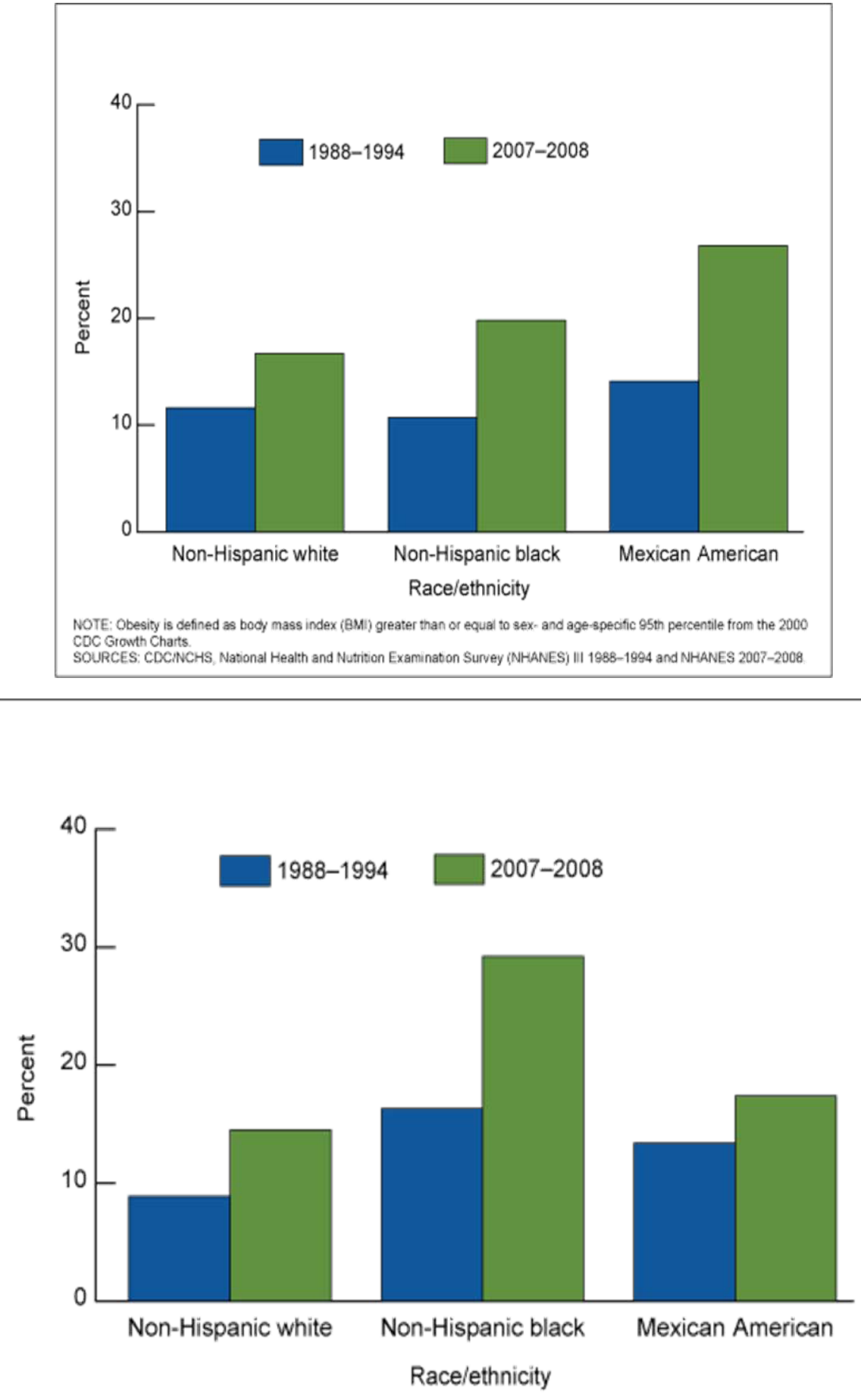

NOTE: Obesity is defined as body mass index (BMI) greater than or equal to sex-and age-specific 95th percentle from the 2000 CDC Gromth Charts.

SOURCES CDCNCHS, National Health and Nutntion Examination Survey (NHANES) III 1988-1994 and NHANES 2007-2008

Fig. 6.

$\mathrm{a}$ and $\mathrm{b}$. Among children and adolescents, Mexican American males and African American females are more likely to have a higher BMI

Psychiatr Clin North Am. Author manuscript; available in PMC 2012 December 1. 


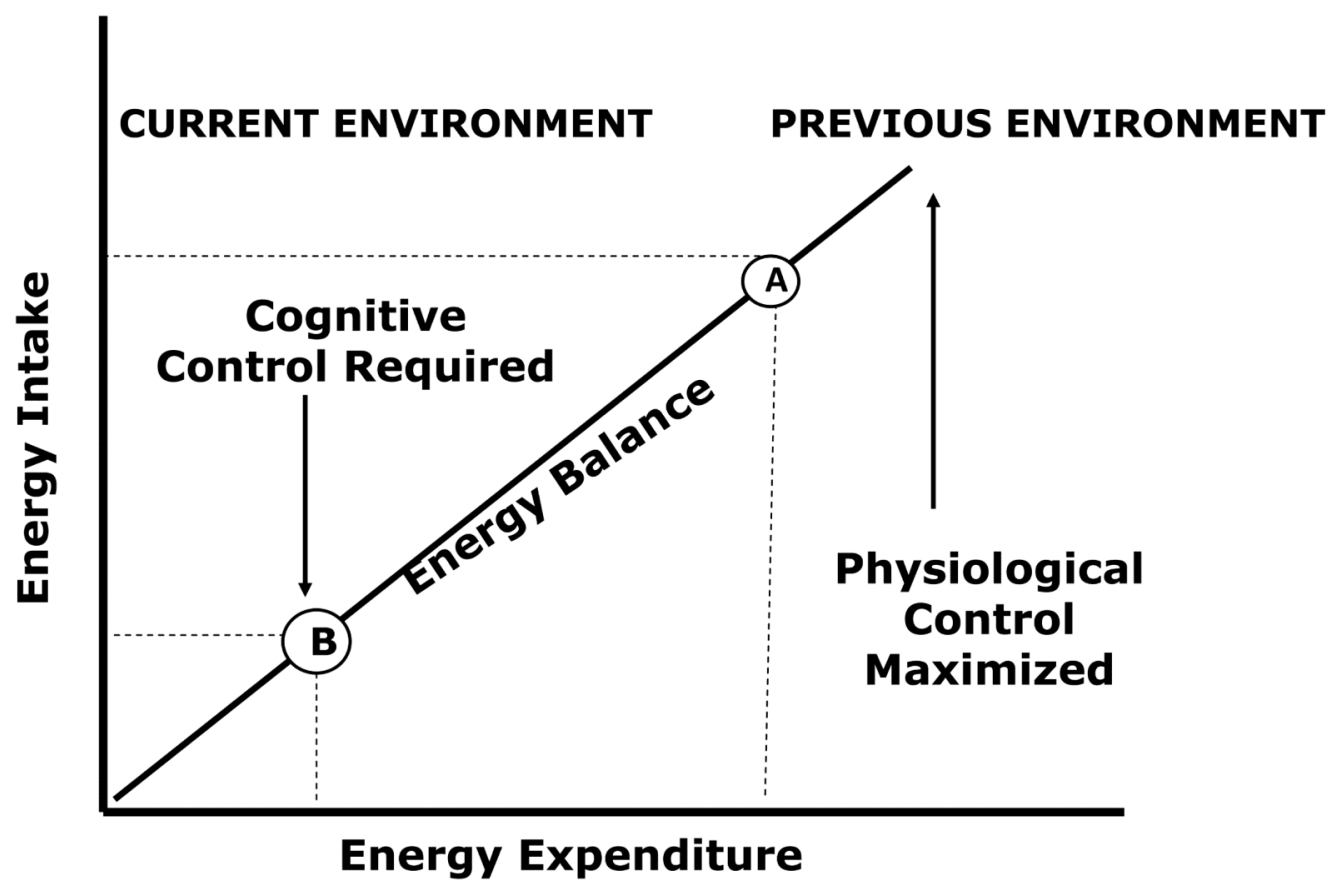

Fig. 7.

Both the environment and behavior must be addressed in assessing energy balance. 


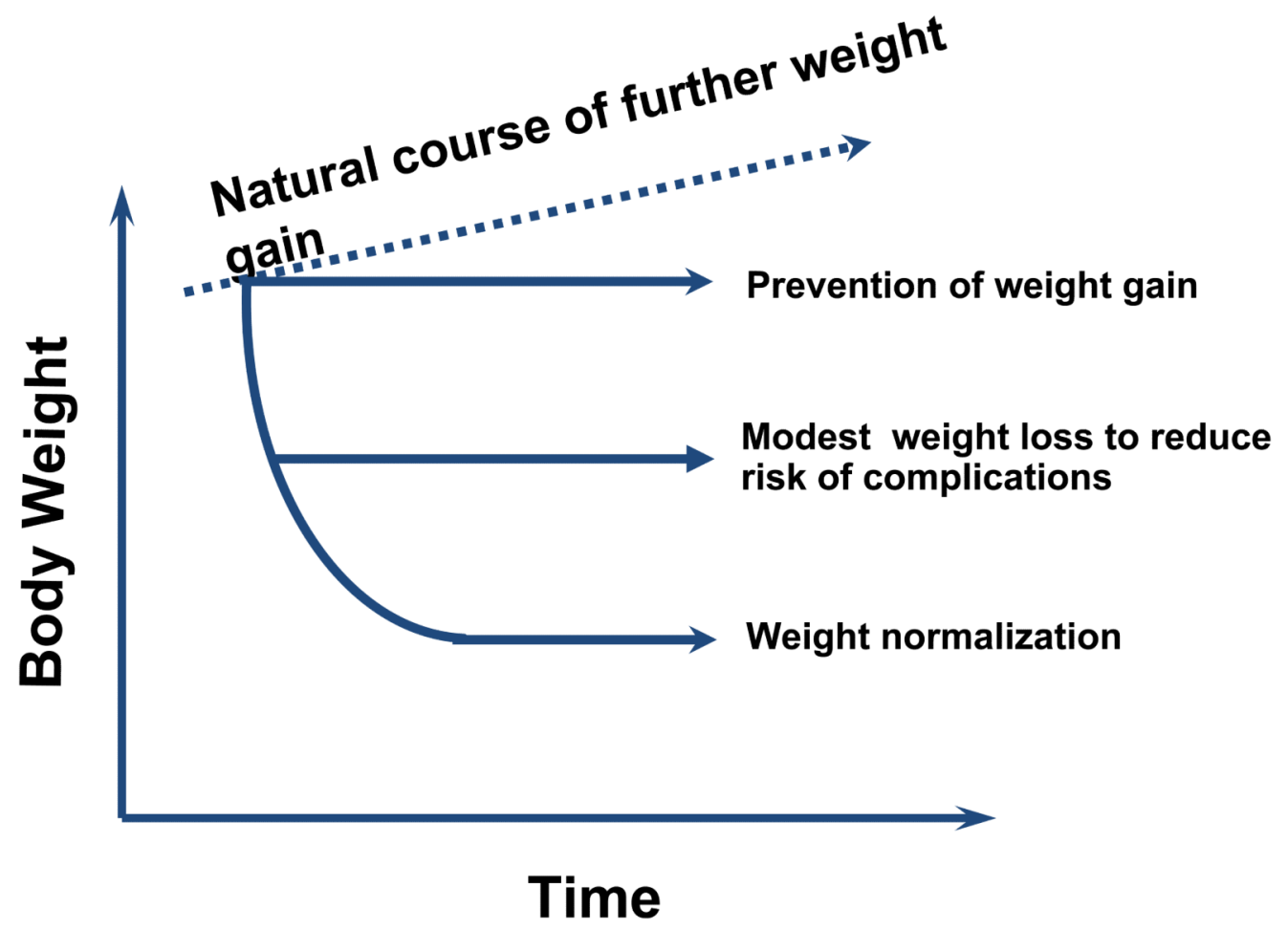

Fig. 8.

Strategies to reverse the obesity epidemic. Adapted from Rossner, 1992—need full citation here. 


\section{Table 1}

Categories of BMI and disease risk* relative to normal weight and waist circumference.

\begin{tabular}{|l|c|c|c|c|}
\hline & BMI kg/m & Obesity Class & Men $\leq \mathbf{1 0 2} \mathbf{c m}(\leq \mathbf{4 0}$ in $)$ Women $\leq \mathbf{8 8} \mathbf{~ c m}(\leq \mathbf{3 5}$ in $)$ & $>\mathbf{1 0 2} \mathbf{~ c m}(>\mathbf{4 0}$ in $)>\mathbf{8 8} \mathbf{~ c m}(>\mathbf{3 5}$ in $)$ \\
\hline Underweight & $<18.5$ & & - & - \\
\hline Normal+ & $18.5-24.9$ & & - & - \\
\hline Overweight & $25.0-29.9$ & & Increased & High \\
\hline Obesity & $30.0-34.9$ & I & High & Very High \\
\hline & $35.0-39.9$ & II & Very High & Very High \\
\hline Extreme Obesity & $\geq 40$ & III & Extremely High & Extremely High \\
\hline
\end{tabular}

* Disease risk for type 2 diabetes, hypertension, and CVD

${ }^{+}$Increased waist circumference can also be a marker for increased risk even in persons of normal weight.

The table is reprinted from reference 5 .

Data from Clinical guidelines on the identification, evaluation, and treatment of overweight and obesity in adults: executive summary. Expert Panel on the Identification, Evaluation, and Treatment of Overweight in Adults. Am J Clin Nutr 1998;68:899-917. 
Table 2

Prevalence of obesity by race and gender

\begin{tabular}{|l|l|l|}
\hline Race & Males & Females \\
\hline Caucasian & 31.9 & 33.0 \\
\hline African American & 37.3 & 49.6 \\
\hline Mexican American & 35.9 & 45.1 \\
\hline
\end{tabular}

Source: Prevalence of Overweight, Obesity, and Extreme Obesity Among Adults: United States Trends 1976-1980 Through 2007-2008. http://www.cdc.gov/NCHS/data/hestat/obesity_adult_07_08/obesity_adult_07_08.pdf 